\title{
LA TONADILLA DE NOÉ: LA TORTUGA Y LA BALLENA, PROTAGONISTAS DEL DILUVIO UNIVERSAL EN UN CUENTO DE MARÍA TERESA LEÓN
}

\author{
MaRía Lourdes NúÑEZ MoLina \\ Investigadora independiente
}

\begin{abstract}
RESUMEN
Algunos cuentos de María Teresa León están protagonizados por animales que el lector relaciona con fábulas y cuentos populares (el oso, el lobo, el zorro, el águila...), pero sus historias suelen ser innovadoras. Así sucede en «La Tortuga 427» (publicado en Rosa-Fría, patinadora de la luna, 1934), donde la autora reescribe el mito del diluvio universal, destinando un papel crucial a dos animales literarios: uno vinculado con las fábulas -la Tortuga-, otro con los bestiarios -la Ballena-, para transmitir un mensaje moral. Además, destacaré cómo los recursos lúdicos contrastan con el desilusionado desenlace, conectando con textos posteriores de la autora.
\end{abstract}

Palabras Clave: cuento, diluvio universal, bestiarios, tortuga, ballena.

\section{Abstract}

Some María Teresa León's tales are starred by animals that the reader related to fables and folktales (bear, wolf, fox, eagle...), but their stories are often innovative. This happens in «La Tortuga 427» (published in Rosa-Fría, patinadora de la luna, 1934), where the author rewrites the Flood myth, allocating a crucial role to two literary animals: one linked with the fables - the Turtle- the other with the bestiary -the Whale-, to convey a moral message. In addition, I will highlight how the recreational resources contrast with the disappointed outcome, connecting with later texts of the author.

KEY WORDs: tale, flood myth, bestiary, turtle, whale.

Gran defensora del arte del «cuento hablado», María Teresa León Goyri entendía que, si la narradora hila, teje e «inventa ante el auditorio» ${ }^{1}$, el oyente puede transformar esas historias, perpetuando y adaptando la tradición a los tiempos modernos. Durante la infancia y adolescencia, se apasiona por la lírica popular y, sobre todo, por el

Recibido: 03-03-2016 / Aceptado: 13-07-2017

${ }^{1}$ León, M. T., «La narradora», La Gaceta Literaria, 85 (1 de julio de 1930), p. 8. 
Romancero -atenta a «un gramófono de cilindro que cantaba romances con la voz del tiempo cascada y rota ${ }^{2}-$. Más tarde, a lo largo de su trayectoria como escritora, enhebrará en sus textos aquellas estrofas aprendidas en la casa de su tía María Goyri. Asimismo, la lectura de poemas épicos, leyendas, fábulas, cuentos maravillosos, cuentos de animales..., dejaría una huella en su imaginación y en su memoria, ya que concebirá ciertos relatos, imprimiéndoles una visión contemporánea en la que, sin embargo, se perciben ecos de la literatura medieval.

En el conjunto de su obra cuentística, los animales literarios ocupan un lugar destacado, especialmente en tres libros: Cuentos para soñar (1928), Rosa-Fría, patinadora de la luna (1934) y Fábulas del tiempo amargo (1962). El primero está dedicado a su primer hijo, Gonzalo: «Para mi hijo iba inventando cuentos al volar de mi imaginación. Hoy, en sus manos [...], dejo mi libro, lleno de amor a los viejos temas de mi infancia, avalorado por el arte de una compañera de juegos» ${ }^{3}$. Fue alumbrado por la preocupación de la autora en cuanto a la labor educativa de las madres y reúne personajes de los cuentos infantiles como Blancanieves, Cenicienta, Aladino, el Gato con Botas, la Bella Durmiente... La protagonista, Nenasol, se adentra en el reino de las hadas, donde conoce a uno de aquellos dragones protectores de princesas y de tesoros, un «monstruo [...], todo brillante como si fuera de esmeralda» que «crujía al moverse y despedía chispas $»^{4}$. Entusiasmada por restaurar la magia, la pequeña recorre el mundo de los hombres, en compañía de Pulgarcito ${ }^{5}$ y del Pájaro Azul.

Tras la publicación de La bella del mal amor (1930), cuando María Teresa y Rafael Alberti ya han unido sus vidas, comienza a gestarse Rosa-Fría, patinadora de la luna. Con este libro, destinado al lector infantil, ahonda en los cuentos protagonizados por humanos y animales. Además de ilustrar cada una de las historias, la influencia de Alberti - en concreto de sus poemarios Marinero en tierra (1925) y El alba del alhelí (1927)- se evidencia en tres ${ }^{6}$ de las nueve narraciones que forman la colección: «Rosa-

${ }^{2}$ León, M. T., Memoria de la melancolía, Gregorio Torres Nebrera (ed.), Madrid, Clásicos Castalia, 1999, p. 88. Más adelante, recuerda que los romances que escuchaban en el gramófono habían sido recogidos por María Goyri y Ramón Menéndez Pidal «durante su viaje de novios, siguiendo la ruta del Cid hacia su destierro» (p. 151).

${ }^{3}$ León, M. T., Cuentos para soñar, María Goyri de Menéndez Pidal (pról.) y Rosario de Velasco (ilus.), Madrid, Editorial Edaf-Santillana Ediciones Generales, 2004, p. 7. La dedicatoria revela el influjo de la fantasía en el desarrollo de los niños: «Y era un día de nieve cuando al niño le regalaron el primer libro de cuentos. Desde entonces dejó el caballo y el aro, y casi olvidó la bicicleta. El niño encontraba en su cabecita el poder de crear [...]. Una briznita de inquietud brotaba en su alma [...]. Yo veía crecer su fantasía, afirmarse su personalidad».

${ }^{4}$ León, M. T., Cuentos para soñar, ob. cit., p. 15.

${ }^{5}$ Torres Nebrera, G., Los espacios de la memoria (La obra literaria de María Teresa León), Madrid, Ediciones de la Torre, 1996, p. 69, ha señalado el paralelismo entre las aventuras de Nenasol y Pulgarcito y «el apólogo del ratón de campo trasplantado a la ciudad».

${ }^{6}$ La historia de «Rosa-Fría, patinadora de la luna» surge de un soneto homónimo publicado en Marinero 
Fría, patinadora de la luna», «La Tortuga 427» (objeto de mi estudio), «El lobito de Sierra Morena», «El Oso poeta», «El gallo Perico», «Flor del Norte», «Juan Bobo», «El ladrón de islas» $\mathrm{y}$ «El pescador sin dinero». El tercero y el séptimo son versiones de cuentos populares de tradición oral, atesorados, catalogados y estudiados por Aurelio M. Espinosa ${ }^{7}$. Se ha subrayado repetidamente la conjunción entre tradición y vanguardia, como uno de los rasgos estilísticos más llamativos de la obra, por tanto, es un aspecto en el que no haré hincapié ${ }^{8}$.

Ya en el contexto del exilio republicano, María Teresa publica Morirás lejos (1942), donde reúne los diez relatos de Cuentos de la España actual (1935) y ocho nuevos que pueden interpretarse en la corriente de la crítica social. «La hora del caballo» cierra la obra y destaca por ofrecer una visión de los héroes anónimos -los olvidados por la Historia-, valiéndose de lo maravilloso. El cuento narra la llegada de la yegua Rabona a Nueva España (México) en un barco gobernado por Hernán Cortés. Se contrasta la búsqueda de gloria que guía a hombres como su amo, Juan Sedeño, frente al protagonismo rehusado por la Rabona. A la yegua solo le preocupa el cuidado de unos potrillos que poblarán el nuevo territorio, pero a los que ella no podrá criar:

¡Pobrecita Rabona! Miles de flechas traspusieron la valla de su piel tan humilde [...].

Iban a buscar su corazón. Le abrieron el vientre...

Una tropa de potrillos milagrosos relinchó, saltando a la vida. De todos los colores: verdes, blancos, azules, rosas... ¡Una catarata de potrillos para la extensión nueva! Saltaron la selva virgen, las pirámides, los volcanes, los ríos, y se hundieron en el día de América que estaba amaneciendo?.

en tierra, en Alberti, R., Marinero en tierra; La amante; El alba del alhelí, Robert Marrast (ed.), Madrid, Clásicos Castalia, 1987, pp. 86-87. «Blanca-Nieve, flor del norte, / se fue al mar del mediodía [...] / ¡Se habrá derretido ya!», son los versos del «Madrigal de Blanca-Nieve» (Alberti, R., Marinero en tierra [...], ob. cit., p. 140) que inspiran «Flor del Norte», donde María Teresa parodia este cuento infantil a través de sus motivos más conocidos: el espejo de la madrastra, el peine envenenado, el cazador, la urna de cristal... Por último, «El pescador sin dinero» es un cuento maravilloso que enriquece la historia del poema de igual título publicado en El alba del alhelí (Alberti, R., Marinero en tierra [...], ob. cit., pp. 191193).

${ }^{7}$ Espinosa, A. M., Cuentos populares recogidos de la tradición oral de España, Luis Díaz Viana y Susana Asensio Llamas (intr. y revis.), Madrid, CSIC, 2009. «Juan Bobo» (núm. 193), pp. 628-630 y «El lobito de Sierra Morena» (núm. 204), pp. 699-700.

${ }^{8}$ Bravo-Villasante, C., «María Teresa León, mujer de letras», en A.A.V.V., María Teresa León, Valladolid, Junta de Castilla y León, Editorial Servet-Cuesta, 1987, pp. 17-19; Estébanez Gil, J. C., Ma Teresa León. Estudio de su obra literaria, Burgos, Editorial La Olmeda, 1995, pp. 122-145; Guerrero Ruiz, P., y Caro, M. T., «María Teresa León y la literatura infantil. Los cuentos populares», Letras Peninsulares, v. 17.1 (2004), pp. 62-66; Puerto, J. L., «María Teresa León: fábula y poesía (Rosa-Fría, patinadora de la luna)», en A.A.V.V., María Teresa León (1905-1988), Madrid, Ayuntamiento de Madrid, Centro Cultural de la Villa, 1990, s/ p; y Torres Nebrera, G., Los espacios de la memoria, ob. cit., pp. 79-84.

${ }^{9}$ León, M. T., Fábulas del tiempo amargo y otros relatos, Gregorio Torres Nebrera (ed.), Madrid, Cátedra, 2003, p. 261. Si atendemos a las palabras de María Teresa en Memoria de la melancolía, ob. cit., p. 255: «el oro del Perú» era acarreado por «animales llevados como niños en las naves, dándose de cabezazos hasta llegar a tierra firme, como cuenta Bernal Díaz del Castillo que sucedió con los dieciséis primeros 
En octubre de 1962 Ecuador 0 00”. Revista de Poesía Universal (México) publica cinco simbólicas Fábulas del tiempo amargo. Dos cuentan con animales entre sus personajes. "Comed, comed, que ya estoy invitada» es un cuento de hadas moderno en el que una muchacha metamorfoseada en corza blanca es cazada en el bosque, cocinada y devorada en un banquete que trasluce la crueldad humana. En «El viaje» María Teresa recurre a los cuentos esópicos para relatar el final de la Guerra Civil y el inicio del destierro. El Zorro y el Lobo (alegorías del franquismo) acosan a una chica con pérfidos consejos y artimañas para que no huya, pero ella, a pesar del dolor por dejar atrás su tierra, escapa sentada «entre el plumón del Águila» ${ }^{10}$ y cruza el océano para comenzar una nueva vida.

Esta breve revisión sirve para apuntar cómo la escritora suele adoptar una visión simbólica, cuyos orígenes «se remontan a la época clásica», en la que confluyen «la moralización del mundo animal, en el que cada especie se podría asimilar a una virtud o un vicio humano (fruto de la tradición fabulística iniciada por Esopo), y el recurso a lo mágico, lo mítico, lo maravilloso y lo fantástico» ${ }^{11}$ de raigambre oriental. Idea que trataré de desgranar mediante el análisis de «La Tortuga $427 »^{12}$, un cuento de animales que engarza con la tradición literaria de las fábulas por su finalidad lúdica y didáctica.

María Teresa León reescribe el mito del diluvio universal, destinando un papel esencial a dos animales literarios, uno relacionado con las fábulas -la Tortuga- y otro con los bestiarios -la Ballena-, con el fin de transmitir un mensaje moral. La Tortuga, único testigo de los «prodigios» del diluvio, quien «enseñó a Noé el nuevo sol del mundo» ${ }^{13}$, constatará que la salvación de la humanidad fue inútil, que los males de los hombres no han cambiado. Y la Ballena, auténtica arca de Noé, cuyo único deseo era tener un «sitio en la historia del diluvio» (p. 59), será olvidada.

La narradora nos presenta un curioso salón de té en el que tortugas, ranas, burros, e incluso algún elefante, meriendan junto a unas señoritas que parecen no advertir su presencia, debido a que los animales imitan su conducta: «fumar, cruzar las piernas...» (p. 54). Una tarde la Tortuga 427 sustituye al señor que la ha amaestrado,

caballos desembarcados en el continente nuevo, [...] uno era yegua y parió en el camino...», se infiere que el origen del cuento se halla en Historia verdadera de la conquista de la Nueva España (1632).

${ }^{10}$ León, M. T., Fábulas del tiempo amargo y otros relatos, ob. cit., p. 316.

11 Morgado García, A., «La visión del mundo animal en la España del siglo XVII: El Bestiario de Covarrubias», Cuadernos de Historia Moderna, 36 (2011), p. 72.

${ }^{12}$ Este cuento encabezará la traducción al italiano de la colección Rosa-Fría, patinadora de la luna, publicada en 1966 con el título La Tartaruga 427.

${ }^{13}$ León, M. T., Rosa-Fría, patinadora de la luna, Ma Asunción Mateo (pról.) y Rafael Alberti (ilus.), Madrid, Ediciones de la Torre, 1990, p. 61. Todas las citas corresponden a esta edición, en adelante el número de página se colocará entre paréntesis en el texto. 
pero no es capaz de comportarse como las mujeres del salón, e intenta recuperar su identidad, pidiendo «lechuga, cucarachas, al brazo de una camarera que no lo oyó» (p. 54). Como es ignorada, se refugia en su caparazón. Entonces el sonido de la lluvia le hace evocar la «tonadilla del diluvio» que cantó Noé para congregar a los animales en el monte. En ese momento, nos traslada a una época remota, «un día» en que «[p]or los cielos volaban pájaros, echando el primer abono sobre el mundo, lleno de malezas, que aún no se habían convertido en árboles copudos o esbeltos» (p. 56).

En esta primera parte del cuento, la función de la narradora es doble. Por un lado, apela a la imaginación de los lectores para que crean que animales y humanos conviven sin ser conscientes de ello: «¿Que no es costumbre verlos? Pues yo os aseguro que los animales circulan entre nosotros con tanta familiaridad que ni los vemos» ( $\mathrm{p}$. 53). Por otro, trata de convencernos de que la creencia en el arca de Noé ha sido un error histórico, pues los animales fueron «salvados en la ballena» (p. 54). De ese modo, se funden dos episodios bíblicos: el del Diluvio y el del profeta Jonás engullido por la ballena. Esta asociación es posible, si consideramos el sentido alegórico de ambos: salvación y renovación individual y colectiva ${ }^{14}$.

En la Biblia se dice: «Dispuso Yahveh un gran pez que se tragase a Jonás, y Jonás estuvo en el vientre del pez tres días y tres noches» (Jon 2,1) ${ }^{15}$. Los bestiarios medievales prosiguen las descripciones y relatos del Phisiologus, «texto griego paleocristiano que conjuga la filosofía natural clásica con los misterios de la naciente religión cristiana» ${ }^{16}$, y relacionan ese gran pez con una ballena. En los bestiarios se explica cómo es confundida con una isla ${ }^{17}$ o se la representa como un enorme monstruo, engullidor

\footnotetext{
${ }^{14}$ Relación ya establecida en la literatura de la Edad Media: el Poema de Mio Cid, el Poema de Fernán González, los Milagros de Nuestra Señora y Loores de Nuestra Señora de Gonzalo de Berceo, el prólogo al Libro de Buen amor de Juan Ruiz, Arcipreste de Hita, el Tirant lo Blanch de Joanot Martorell... Cada autor adaptó «a las necesidades narrativas» el Sacramentario de Gelón, una de las variaciones del Ordo Commendationis Animae, plegaria cristiana que invocaba a diversas figuras bíblicas, entre ellas a Noé — «Libera Domine animam servi tui illi sicut liberasti Noae per diluvium»- y a Jonás — «Libera Domine animam servi tui illi sicut liberasti Jonam de ventri coeti»-. En Gómez Narros, J., «Un ordo litúrgico latino convertido en literatura romance: el Ordo Commendationis Animae en la épica española», Dicenda. Cuadernos de Filología Hispánica, Núm. Especial, vol. 33 (2015), pp. 89-104. Jonás es más mencionado en estos textos que Noé. Juntos aparecen en la plegaria de López de Ayala, P., Libro Rimado de Palacio, Kenneth Adams (ed.), Madrid, Cátedra, 1993, estrofas 798 y 801, pp. 271-272: «Señor, Tú que a Noé del deluvio libraste, / en las muy grandes ondas tu amor le mostraste [...]. Señor, Tú que a Jonás del vientre de ballena / libraste de perigro en que estava en pena».
}

${ }^{15}$ Biblia de Jerusalén, Bilbao, Editorial Española Desclée de Brouwer, 1976, p. 1271.

16 Martín Pascual, L., «La tradición animalística en Italia: el Bestiario toscano», Cultura Neolatina, LxxII, 1-2 (2012), p. 145.

${ }^{17}$ El Fisiólogo. Bestiario medieval, Nilda Guglielmi (ed.), Madrid, Ediciones Eneida, 2005, p. 159 n. 150: «La leyenda de la ballena a la cual se confunde con una isla, por su extensión e inmovilidad, tiene origen griego, atestiguado por muchas obras. [...] desde los Argonautas hasta Los viajes de Gulliver [...]. La versión que da el Fisiólogo es idéntica al cuento hebreo atribuido a Rabbah bar Hana, un rabino de Babilonia (fines del s. III). En Las mil y una noches, en los viajes de Simbad el marino, encontramos una 
de peces pequeños, también «capaz de devorar» ${ }^{18}$ al ser humano. Veamos algunos ejemplos:

Hay un gran monstruo en el mar, llamado aspidochelone. Tiene dos atributos, y el primero es el siguiente: cuando tiene hambre, abre las mandíbulas de par en par, y de ellas sale un aroma dulcísimo. Y todos los pececillos se arremolinan en bandadas y bancos en torno a la boca de la ballena, que los engulle [...].

El otro atributo de la ballena reza así: el monstruo es enorme, como una isla. Los navegantes, en su ignorancia, fondean junto a él su embarcación, como en la orilla de una isla. Encienden fuego encima para preparar su comida; cuando el monstruo siente el calor, se hunde en las profundidades del mar y arrastra consigo la nave y a todos los marinos.

Physiologus griego.

Cetus es una bestia enorme, que siempre vive en el mar; toma la arena del mar y la extiende sobre la espalda. Luego, se yergue sobre el mar y queda inmóvil. El navegante la ve, y cree que es una isla; allá va a atracar, y a preparar su comida. La ballena nota el fuego, la nave y las gentes, y se zambulle; si puede, los ahogará.

Bestiario de Philippe de Thaün.

Existe un monstruo en el océano, llamado aspidodelone en griego. Por otra parte, lo llaman aspidotortuga en latín. También se le denomina ballena (cetus) por lo espantoso de su cuerpo, y porque fue este animal el que engulló (excipit) a Jonás, y su vientre era tan grande que las gentes pensaban que se trataba del infierno. El propio Jonás dijo: «El me oyó desde el vientre del infierno».

Bestiario latino en prosa conservado en la Biblioteca Universitaria de Cambridge ${ }^{19}$.

Al caracterizar a la Ballena, María Teresa emplea sutiles referencias de las descripciones de los bestiarios. El cuento proyecta, por tanto, la imagen de una «ballena prodigiosa» (p. 60), armonizando el humor con la función ejemplar de estos. Muchas ballenas llevan familias en «el lomo, náufragos que salvaban sus patas finas de grullas, su piel listada de cebras» (p. 59), es decir, actúan como islas; pero solo una «desalquilada» accede a la petición de Noé de llevarlos «dentro» (p. 59). Todos los animales van entrando, menos la Tortuga que, «siempre tan desgraciadita, sola, sola bajo el diluvio», resiste en el «lomo del monstruo», desde donde oye «músicas» que salen de su «vientre» (p.60). Cuando concluye el diluvio, los hijos de Noé (encarnan los vicios), como «último acto de amor filial», se acercan «a limpiarle», luego, se dispersan

\footnotetext{
narración semejante».

${ }^{18}$ Acosta, V., Animales e imaginario: la zoología maravillosa medieval, Caracas, Universidad Central de Venezuela, Dirección de Cultura, 1995, p. 202. Acosta señala que este «tema es típico de los relatos míticos y de los cuentos de hadas, en los que para iniciarse, el héroe debe entrar a las fauces del monstruo [...], permanecer en su interior, y luego salir, expulsado o vomitado por él, es decir, renacido a otra vida» (p. 202).

${ }^{19}$ Bestiario medieval, Ignacio Malaxecheverría (ed.), 3ª ed., Madrid, Ediciones Siruela, 2002, pp. 111-113.
} 
por una «Tierra sin veredas» (p. 61); mientras que la Tortuga y la Ballena (encarnan las virtudes), al ser ignoradas por Noé, se miran «con una pena fraterna y humana, la más humana que ha sostenido el mundo, y ellas también se fueron por distintos caminos...» (p. 62, la cursiva es mía).

La Tortuga es un personaje enigmático por el «inmenso número 427» (p. 53) que luce en su caparazón, sobre el que la gente se pregunta «si era una rifa, si salía de presidio, si era un animalito de la buena suerte» (p. 62), pero al que la narradora se había referido como «su tortura» (p. 53). Lo que permite una doble interpretación. Por un lado, podría ser una sutil alusión a la fábula de Esopo, «Zeus y la tortuga», en la que se relata cómo Zeus castiga a la tortuga por ser la única que no ha asistido a su banquete de bodas, decidiendo «que llevase consigo su casa a cuestas» ${ }^{20}$. Por el otro, podría ser un número mágico tras el que se oculta el misterio de la humanidad (el siete, el diecisiete y el veintisiete son números que se repiten en el relato bíblico del diluvio). En cualquier caso, este 427 rayado con «tiza», al final del cuento, será borrado por el agua, y con él su hermético significado ${ }^{21}$.

Aunque en el presente no tenga ni «historia», ni «jerarquía» por culpa de Noé (p. 62), ella fue la verdadera protagonista del mito. Al recordar el comienzo del diluvio, la narradora revela que la Tortuga fue la primera en reconocerlo («-Padre de todos, me estoy ahogando; esto es el diluvio» p. 56); ella fue quien pensó en la ballena como medio de salvación, porque la madera estaba húmeda; quien, abandonada por Noé y atropellada por el resto de animales, sobrevivió en el lomo de la Ballena, siendo testigo excepcional de diversas maravillas. Por ejemplo, vio «cómo el décimo día se rompieron los tirantes que unían la Tierra con la luna», el «día 21 apareció el sol con aros de colores y damas en calesas, girando» (p. 60). Y, como la paloma no regresaba, «el día 40» la Tortuga anunció su final «con una hojita de perejil en la boca» (p. 61).

La escena en la que la paloma vuelve al arca con una rama verde de olivo (Gn $8,11)$ es una de las más difundidas; sin embargo, la autora la sustituye por la hojita de perejil. Un cambio que guarda relación con su gusto por lo popular, ya que el perejil se encuentra en canciones con sentido simbólico amoroso o satírico, y en rimas de niños como esta:

Culantrillo llama a la puerta;

perexil:-¿Quién está aý?

\footnotetext{
${ }^{20}$ Esopo, Fábulas, López Casildo, G. (intr. y notas), 6 6a reimpresión, Madrid, Alianza Editorial, 2006, p. 76.

${ }^{21}$ Un sentido simbólico análogo se encuentra en el soneto que Rubén Darío dedicó a Amado Nervo, en cuyo primer cuarteto leemos: «La tortuga de oro camina por la alfombra / y traza por la alfombra un misterioso estigma; / sobre su carapacho hay grabado un enigma / y un círculo enigmático se dibuja en su sombra». En Darío, R., Antología, Octavio Paz (pról.) y Carmen Ruiz Barrionuevo (ed.), $2^{a}$ ed., Madrid, Espasa Calpe (Colección Austral 269), 1994, p. 196.
} 
-Hiervabuena soy, señora, que vengo por teronjil ${ }^{22}$.

Pero, sobre todo, se percibe la influencia del segundo y del tercer verso de la «Nana de la Tortuga» que Alberti publicó en Marinero en tierra:

Verde, lenta, la tortuga.

¡Ya se comió el perejil,

la hojita de la lechuga!

¡Al agua, que el baño está

rebosando!

$¡ A l$ agua,

pato!

Y sí que nos gusta a mí

y al niño ver la tortuga

tontita y sola nadando ${ }^{23}$.

Como ya se indicó, el cuento forma parte de un libro dirigido a un público infantil. Por ello, la autora emplea el humor en muchos momentos del relato. Por ejemplo, cuando transmite la imagen de un Noé despistado, que «tardó en comprender» lo que representaba la lluvia, porque «no se lavaba»y tuvo que preguntar a la viña qué hacer; esta «estuvo a punto de recomendarle los impermeables; pero saboreaba el agua de tal manera por todos sus pámpanos, que no le dijo nada» (p. 56); o cuando narra la transformación del mundo animal: «Los trajes se ajustaban tirantes a sus nuevos tamaños. Solo los elefantes y sus hijos dejaban un poco que desear. Decididamente, se visten mal por las mañanas» (p. 61). El tono lúdico se logra, además, gracias a la repetición de la alegre tonadilla, cuya musicalidad (creada por la combinación de paralelismos y aliteraciones) guía a los animales hacia el montecillo:

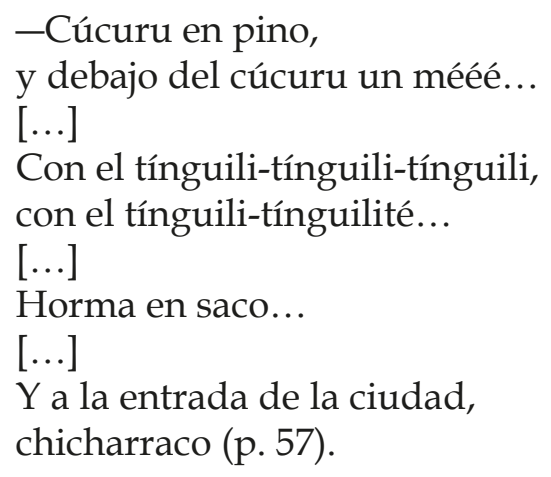

${ }^{22}$ Nuevo corpus de la antigua lírica popular hispánica (siglos XV a XVII), Margit Frenk Alatorre (ed.), vol. II, México, Facultad de Filosofía y Letras-UNAM, El Colegio de México, FCE, 2003, p. 1496. Una de las canciones de amor dolorido más citadas es la que Federico García Lorca recogió en su Colección de cantares populares antiguos con el título «Las tres hojas», en la que la verbena, la lechuga y el perejil presentan connotaciones eróticas: «Debajo de la hoja / del perejil / tengo a mi amante malo, / no puedo ir». En Piñero, P., «Lorca y la canción popular. Las tres hojas: de la tradición al surrealismo», Culturas Populares. Revista Electrónica, 6 (enero-junio 2008), p. 5. Disponible en: http://www.culturaspopulares. org/textos6/articulos/pinero.pdf [consultado 08-06-2015].

${ }^{23}$ Alberti, R., Marinero en tierra [...], ob. cit., pp. 103-104. 
Sin embargo, el desenlace contrasta con este ambiente festivo y con el vitalismo de los otros cuentos de la colección. De nuevo en el presente, la Tortuga, que había sido ignorada por la camarera, además, ahora es maltratada por señoras que entran y salen del salón de té «con cajas de bombones y paquetitos de guantes» (p. 62). María Teresa refleja la frivolidad y crueldad de la sociedad burguesa - a la que ella pertenecía y de la que escapó ${ }^{24}-$. Cuando descubren que solo es una tortuga, la expulsan, condenándola a la soledad y al olvido, como ya hiciera Noé, quien únicamente «[p]or el interior de sus ojos ciegos» (p. 61), pudo presentir cómo sus hijos repoblaban la Tierra y establecían una nueva sociedad que cometería los mismos pecados que dieron lugar al diluvio. Nunca hubo redención, pues el sufrimiento, el sacrificio, la falta de solidaridad y de hermandad arbitran el destino del ser humano:

En la calle, el invierno dormía helado en los troncos y en las aceras [...]. De un puntapié, a la Tortuga la dejaron en el arroyo. Una corriente que huía por un canalillo se la llevó. La tiza que formaba el 427 se fue quedando atrás. Y ella se despeñó por una alcantarilla (p. 63).

Este final desencantado conectaría con las cinco Fábulas del tiempo amargo y con La libertad en el tejado, otra "“fábula amarga"», según Torres Nebrera ${ }^{25}$. María Teresa León volverá a plantear el tema de la salvación de la humanidad en esta obra de teatro ${ }^{26}$, cuya acción se desarrolla en un tejado madrileño, único espacio en el que aún se puede soñar con la libertad, pues las persecuciones, el miedo, el hambre, la muerte... asolan la España franquista. En el segundo acto, el personaje Sabelotodo compara su tejado con el arca de Noé: «Cuentan que Noé recogió sobre su navecilla un animal de cada especie. Sobre la casita se subieron grullas. Y algunas pobres tortugas que se empeñaban en salvarse [...]. ¿Para qué? ¡Ah! Ésa es la gran consternación de los hombres» ${ }^{27}$.

En conclusión, «La Tortuga 427» es un cuento infantil que encierra una intención moralizante y una visión pesimista del ser humano. La Tortuga y la Ballena

\footnotetext{
${ }^{24}$ En las primeras páginas del cuento, la Tortuga se había fijado en «el sombrero verde de una muchacha» (p. 54), en las últimas se dice que «le molestaban las miradas de la gente» (p. 62). Sombreros, guantes, pasteles, paseos, bailes... conforman la imagen de la burguesía burgalesa, tal como María Teresa la reconstruye en Memoria de la melancolía, ob. cit., p. 84: «Y la niña sigue su paseo flanqueada por los bigotes y las barbas, por los sombreros a la moda que su madre trajo de la capital, tan cubierta de miradas que si fuesen hormigas hubiesen devorado a la niña. Pueblo pequeño. Treinta mil habitantes, catedral y cartuja».

${ }^{25}$ León, M. T., Obras dramáticas y Escritos sobre teatro, Gregorio Torres Nebrera (ed.), Madrid, Publicaciones de la Asociación de Directores de Escena de España, 2003, p. 25.
}

${ }^{26}$ Aznar Soler estima que la composición de esta obra podría «situarse en el contexto histórico, político y literario de finales de los años cuarenta o principios de los cincuenta», en León, M. T., Teatro (La libertad en el tejado. Sueño y verdad de Francisco de Goya), Manuel Aznar Soler (ed.), Sevilla, Editorial Renacimiento (Biblioteca del Exilio), 2003, p. 15. Torres Nebrera coincide con esta apreciación: «En una fecha insegura, que podría situarse a partir de la segunda mitad de la década de los años cuarenta», en León, M. T., Obras dramáticas, ob. cit., p. 23.

${ }^{27}$ León, M. T., Obras dramáticas, ob. cit., p. 226. 
encarnan a los más débiles, los marginados, los que no tienen voz en una sociedad deshumanizada que sacrifica a los inocentes desde sus orígenes, según se desprende de la reinterpretación del Diluvio concebida por la autora.

\section{Bibliografía}

Acosta, V., Animales e imaginario: la zoología maravillosa medieval, Caracas, Universidad Central de Venezuela, Dirección de Cultura, 1995.

Alberti, R., Marinero en tierra; La amante; El alba del alheli, Robert Marrast (ed.), Madrid, Clásicos Castalia, 1987.

Biblia de Jerusalén, Bilbao, Editorial Española Desclée de Brouwer, 1976.

Bravo-Villasante, C., «María Teresa León, mujer de letras», en A.A.V.V., María Teresa León, Valladolid, Junta de Castilla y León, Editorial Servet-Cuesta, 1987, pp. 13-22.

DArío, R., Antología, Octavio Paz (pról.) y Carmen Ruiz Barrionuevo (ed.), 2a ed., Madrid, Espasa Calpe (Colección Austral 269), 1994.

Esopo, Fábulas, Gonzalo López Casildo (intr. y notas), 6 a reimpresión, Madrid, Alianza Editorial, 2006.

EspinosA, A. M., Cuentos populares recogidos de la tradición oral de España, Luis Díaz Viana y Susana Asensio Llamas (intr. y revis.), Madrid, CSIC, 2009.

EstébAnez Gil, J. C., Ma Teresa León. Estudio de su obra literaria, Burgos, Editorial La Olmeda, 1995.

Frenk Alatorre, M. (ed.), Nuevo corpus de la antigua lírica popular hispánica (siglos XV a XVII), 2 vols., México, Facultad de Filosofía y Letras-UNAM, El Colegio de México, FCE, 2003.

Gómez Narros, J., «Un ordo litúrgico latino convertido en literatura romance: el Ordo Commendationis Animae en la épica española», Dicenda. Cuadernos de Filología Hispánica, Núm. Especial, vol. 33 (2015), pp. 89-104.

Guerrero Ruiz, P., y CARO, M. T., «María Teresa León y la literatura infantil. Los cuentos populares», Letras Peninsulares, v. 17.1 (2004), pp. 51-67.

Guglielmi, N. (ed.), El Fisiólogo. Bestiario medieval, Madrid, Ediciones Eneida, 2005.

LEÓN, M. T., «La narradora», La Gaceta Literaria, 85 (1 de julio de 1930), p. 8. , La Tartaruga 427, Elena Clementelli (trad. al italiano), Roma, Veutro Editore, 1966.

- Rosa-Fría, patinadora de la luna, Ma Asunción Mateo (pról.) y Rafael Alberti (ilus.), Madrid, Ediciones de la Torre, [1934] 1990.

- Memoria de la melancolía, Gregorio Torres Nebrera (ed.), Madrid, Clásicos Castalia, 1999. 
, Fábulas del tiempo amargo y otros relatos, Gregorio Torres Nebrera (ed.), Madrid, Cátedra, [1962] 2003.

, Obras dramáticas y Escritos sobre teatro, Gregorio Torres Nebrera (ed.), Madrid, Publicaciones de la Asociación de Directores de Escena de España, 2003.

, Teatro (La libertad en el tejado. Sueño y verdad de Francisco de Goya), Manuel Aznar Soler (ed.), Sevilla, Editorial Renacimiento (Biblioteca del Exilio), 2003.

, Cuentos para soñar, María Goyri de Menéndez Pidal (pról.) y Rosario de Velasco (ilus.), Madrid, Editorial Edaf-Santillana Ediciones Generales, [1928] 2004.

López de Ayala, P., Libro Rimado de Palacio, Kenneth Adams (ed.), Madrid, Cátedra, 1993.

MalaXecheverría, I. (ed.), Bestiario medieval, $3^{\text {a }}$ ed., Madrid, Ediciones Siruela, 2002.

Martín PascuaL, L., «La tradición animalística en Italia: el Bestiario toscano», Cultura Neolatina, LXXII, 1-2 (2012), pp. 145-179.

Morgado García, A., «La visión del mundo animal en la España del siglo xvir: El Bestiario de Covarrubias», Cuadernos de Historia Moderna, 36 (2011), pp. 67-88.

PIÑERO, P., «Lorca y la canción popular. Las tres hojas: de la tradición al surrealismo», Culturas Populares. Revista Electrónica, 6 (enero-junio 2008). Disponible en: http://www.culturaspopulares.org/textos6/articulos/pinero.pdf [consultado 08-06-2015].

Puerto, J. L., «María Teresa León: fábula y poesía (Rosa-Fría, patinadora de la luna)», en A.A.V.V., María Teresa León (1905-1988), Madrid, Ayuntamiento de Madrid, Centro Cultural de la Villa, 1990, s/p.

Torres Nebrera, G., Los espacios de la memoria (La obra literaria de María Teresa León), Madrid, Ediciones de la Torre, 1996. 